\title{
Definition and Importance of Psychosexual Care
}

Up until recently, psychosexual problems may have been dealt with on a 'medical basis,' with a quantitative assessment of erectile dysfunction alone [1]. This would not have included patient self-perception, self-esteem, or involving their partner as part of the process [2]. Current studies indicate a much broader aspect needs to be taken [3]. Also included are addressing self-esteem, sexual confidence, physical impact and effect on relationships [4]. Men may also grieve as part of this process [5]. Modern psychosexual care should take that into account [6]. The area of psychosexual care needs to be further developed [7]. In conclusion, a strong psychosexual pathway can address areas of care which would otherwise cause significant issues.

\section{References}

1. Schover LR, Fouladi RT, Warneke CL, Neese L, Klein EA, Zippe C, Kupelian PA. The use of treatments for erectile dysfunction among survivors of prostate carcinoma. Cancer. 2002;95:2397-407.

2. Clark JA, Inui TS, Silliman RA, Bokhour BG, Krasnow SH, Robinson RA, Spaulding M, Talcott JA. Patients' perceptions of quality of life after treatment for early prostate cancer. J Clin Oncol. 2003;21:3777-84.

3. Green HJ, Steinnagel G, Morris C. Using the commonsense and transtheoretical models to understand health behaviours after diagnosis with prostate or breast cancer. Psychooncology. 2011;20:271-2.

4. Hanly N, Juraskova I. Sexual adjustment and self-perception in men following prostate cancer. Support Care Cancer. 2011;1:S332.

5. Bober SL, Sanchez Varela V. Sexuality in adult cancer survivors: challenges and intervention. J Clin Oncol. 2012;30:3712-9.

6. Hanly N, Mireskandari S, Juraskova I. The struggle towards 'the New Normal': a qualitative insight into psychosexual adjustment to prostate cancer. BMC Urol. 2014;14:56.

7. King AJ, Evans M, Moore TH, Paterson C, Sharp D, Persad R, Huntley AL. Prostate cancer and supportive care: a systematic review and qualitative synthesis of men's experiences and unmet needs. Eur J Cancer Care (Engl). 2015;24(5):618-34. 